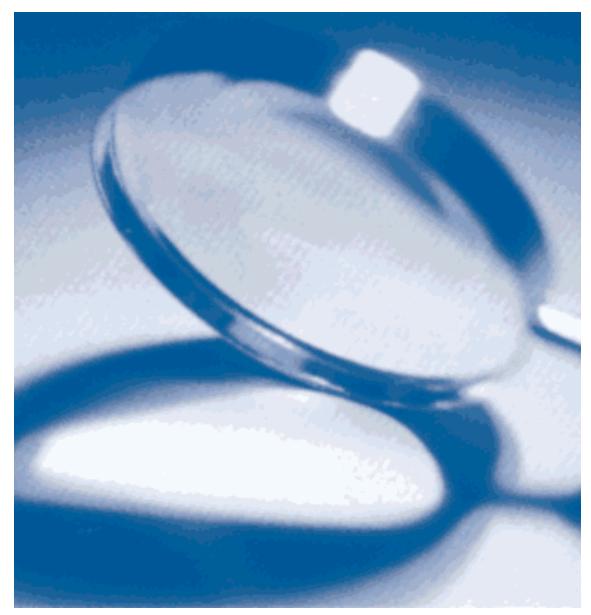

In the Public Eye

News and Features

\title{
Biotechnology company claims to have $97 \%$ of human genes on its database
}

Deborah Josefson, San Francisco

The US biotechnology company Celera Genomics has announced that it has the DNA sequence of $90 \%$ of the human genome in its databases, far outpacing both its own schedule and that of the publicly funded Human Genome Project, which was established in 1990. Celera, founded in May 1998 by Craig Venter, claims to have sequenced $81 \%$ of the genome on its own. It has inferred an additional $9 \%$ from the publicly available data published by the National Institutes of Health in Bethesda, Maryland and by the Sanger Centre in Cambridge, England. The company estimates that $97 \%$ of all human genes are already represented in its database, given a genome size of about 80,000 genes.

Celera, which began its sequencing project in September of 1999, expects to complete the entire sequence by June of 2000 . The achievement, which ushers in the era of pharmacogenomics, is remarkable for its rapid pace and has widespread medical, ethical, and financial implications, especially because Celera is a private commercial enterprise.

The Human Genome Project is being conducted by eight university centers funded by the National Institutes of Health, and by the US Department of Energy and the Sanger Centre in Cambridge, England.

Celera takes a different sequencing approach from that of the public consortium. Celera uses a "shotgun" technique, whereby the DNA of a single anonymous male is sheared into many small and large fragments, which are then reassembled like one puts together a large jigsaw puzzle. This is accomplished by inserting the fragments into a plasmid vector and propagating them in Escherichia coli to produce millions of copies of each fragment. Linking DNA sequences of known length are added to fill in the gaps. When missing pieces are found, the linkers can be deleted. The millions of DNA base pairs are then reassembled with the help of a supercomputer. Celera's computer is believed to be the second most powerful in the world and is active 24 hours a day, 7 days a week.
Two billion base pairs are sequenced by the Celera computer each month.

In contrast, the Human Genome Project is sequencing the DNA of multiple anonymous donors and mapping the genes to a precise location in a more painstaking manner. Their protocol entails inserting the genes into bacterial artificial chromosomes, mapping their positions on these chromosomes, and then sequencing them. The Celera approach skips the mapping and the use of bacterial artificial chromosomes, which can hold on average only 150,000 DNA bases each.

Furthermore, Celera benefits from the publication by the Human Genome Project of all newly sequenced DNA fragments on its website. Under the Bermuda Agreement, the public consortium is obliged to publish newly sequenced genes onto a publicly accessible website within 24 hours. Celera is not bound by such constraints, but takes advantage of them. Because Celera is a commercial enterprise and is obtaining patents for many of the genes that it is discovering, interesting medi$\mathrm{cal}$ and ethical questions arise. The concern has been raised that the success of Celera will lead to decreased federal funding for the public initiative.

The consortium's project is important because the data are free and available to everyone, whereas Celera may choose to withhold some information, particularly that related to genetic polymorphisms, which often disclose information about genes related to certain diseases. More worrisome is the proprietary use of the human genome. Venter has stated that he will eventually make the basic genome widely available but will sell gene sequences related to certain diseases to various pharmaceutical companies and to subscribers to its genome database. Academics and universities will be allowed to subscribe at reduced prices. Celera already has agreements with several blue chip pharmaceutical companies, including Pfizer, Novartis, and Rhône-Poulenc, to provide the gene sequences related to certain diseases. 


\section{Senators introduce bill to improve patient safety}

Fred Charatan, Florida

A bill to improve patient safety is being introduced by two senators, following the publication last November of a report from the Institute of Medicine of the National Academy of Sciences, which claimed that medical errors kill from 44,000 to 98,000 Americans each year.

Mistakes involving the prescribing and dispensing of drugs were the most common errors, resulting in 7000 deaths a year, the report said. President Clinton immediately ordered the Federal Quality Interagency Task Force, which oversees federal health programs for 85 million Americans, to adopt all feasible techniques for reducing medical errors and to report back within 60 days. He has also included more than $\$ 50$ million in the federal budget in new funding for government programs to reduce the nation's rate of medical errors.

Senator Edward Kennedy of Massachusetts, the senior Democrat on the US Senate's health committee, and Democratic senator Joseph Lieberman of Connecticut are introducing the Error Reduction and Improvement of Patient Safety Act. They have bipartisan support from Republican senators James Jefford of Vermont and Dr Bill Frist of Tennessee.

Among other provisions, the bill creates a national center for patient safety in the Department of Health and Human Services' Agency for Health Care Policy and Research. To reach the Institute of Medicine's goal of a $50 \%$ reduction in errors over the next 5 years, the American Hospital Association is working with the Institute for Safe Medication Practices, Huntingdon Valley, Pennsylvania. The Institute is a national leader in the safeguards and reporting of drug treatment and founded the US Pharmacopoeia Medication Errors Reporting System.

Many hospitals now operate computerized programs to make safety checks on drugs ordered for patients. At the LDS (formerly, Latter Day Saints) Hospital in Salt Lake City, Utah, the main computer automatically checks each patient's allergies and drug interactions against laboratory results and other data.

About one third of US hospitals have a system for doctors to enter orders for tests and drugs into a computer, which the Institute of Medicine described as a powerful method for preventing treatment errors. Desktop or mainframe computers can be supplemented by the use of laptop and hand-held devices.

A safety system based on hand-held devices for monitoring drug treatment is now being installed at 170 Veterans Affairs hospitals. A bar code is attached to the pills that the patient takes daily. Nurses swipe the codes on their badges to identify themselves, register the codes on the drug package and the patient's identity bracelet, then check a handheld device to make sure the codes match.

\section{Breast cancer researcher accused of serious scientific misconduct}

Scott Gottlieb, New York

The only trial showing that bone marrow transplants for breast cancer could prolong life is now being sharply questioned after the study's lead investigator was accused of serious scientific misconduct.

The trial, led by Werner Bezwoda, of the University of Witwatersrand, Johannesburg, South Africa, looked at high dose chemotherapy followed by bone marrow transplantation in women whose cancer had spread to 10 or more lymph nodes.

The results of Bezwoda's research were presented last year at the American Society of Clinical Oncology's annual meeting, and his was the only study to show clearly a survival benefit in the high dose regimen.

The University of Witwatersrand has accused Bezwoda of "misrepresenting results of a clinical trial" after an investigation aimed at substantiating Bezwoda's findings failed to produce records needed to confirm his data. Bezwoda denied that there was "any falsification of the data" but refused to elaborate and

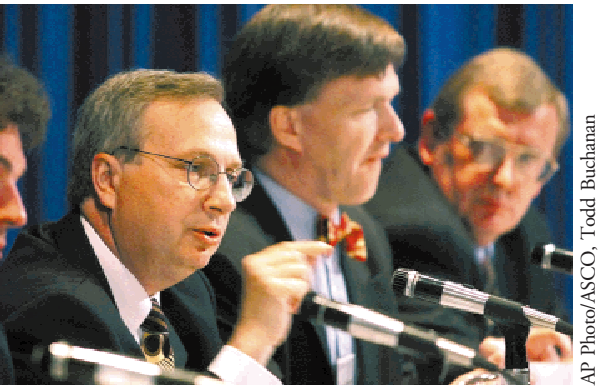

Williams Peters, Jonas Bergh, and Werner Bezwoda (I to $r$ ) discuss value of chemotherapy and bone marrow transplants in fighting breast cancer

referred additional questions to the university.

Previously, the results of four breast cancer studies comparing high dose chemotherapy plus either bone marrow or stem cell transplant with standard chemotherapy found no conclusive benefits from the more aggressive treatment.

The research now in question was the only rigorous study to show any significant benefit to patients who underwent the high dose treatment plus bone marrow transplants. Bezwoda's study involved 154 South African women. After 5 years, $25 \%$ of women in the high dose group had relapsed, compared with $66 \%$ in the group receiving standard treatment. In the high dose group, $17 \%$ had died, compared with $35 \%$ in the standard group.

"Certainly it's upsetting," said Joseph Bailes, president of the American Society for Clinical Oncology. "Obviously it concerned the University in South Africa enough that they brought it to our attention," he said.

Doctors involved in the research into the transplants had known for several months that a team of US doctors was going to South Africa to audit the data from Bezwoda's study, according to Eric Weiner, director of the Breast Oncology Center at the Dana Farber Cancer Institute in Boston. "My understanding is that they were unable to find the records that would substantiate the results," he said. 